\title{
Exploring the benefits of minimobility in the urban context: The case of central Stockholm
}

\author{
William Riggs \\ University of San Francisco
}

\author{
Shivani Shukla \\ University of San Francisco
}

\begin{abstract}
Over the past decade, there has been rapid growth in the development and infusion of new and disruptive transportation. Some of the pivotal emergent technologies range from micro-mobility and bikeshare to ridesourcing that is set to utilize automated vehicles. This paper introduces and defines minimobility that falls between a regular ridesourcing/taxi option and micromobility, and also providing critical logistics services during the era of COVID-19. In Central Stockholm the platform has provided a safe and environmentally friendly mode choice that occupies limited space and efficiently serves on the congested city network. We explore potential economic and environmental benefits of minimobility, discussing the advantages and disadvantages of deploying such a service. While we demonstrate a general increase in VMT, consistent with other work showing increased travel from new mobility, due to the electric platform this increase in customer access to mobility results in minimal GHG impacts. This informs how planners and engineers can explore minimobility platforms not only as reduced emissions solutions to urban transit issues but as tools to increase total mobility particularly for the most vulnerable.
\end{abstract}

Keywords: Minimobility; Transit; Operational Efficiency; Electric Vehicles
Article History:

Received: January 10,

2021

Revised: March 13,

2021

Accepted: March 16, 2021

Available online: Septem-

ber 27,2021

\section{Introduction}

Over the past years, there has been ample discussion of new and disruptive transportation (Riggs 2018). This has included dialogue on emergent technologies ranging from ridesharing or ridesourcing (Circella and Alemi 2018; Hampshire et al. 2017), to micro-mobility like bikes and scooters (Clewlow and Mishra 2017), to automated driving. The ridesharing economy, largely driven by the confluence of technological innovation and demographic change, has filled gaps in the transportation network underserved by the transport industry, be it transit, taxi, biking or walking (Chan and Shaheen 2012; Hall et al. 2018). It has also generated trips that never existed previously.

Copyright 2021 William Riggs and Shivani Shukla.

doi: $10.5198 /$ jtlu.2021.1955

ISSN: 1938-7849 | Licensed under the Creative Commons Attribution - NonCommercial License 4.0.

The Journal of Transport and Land Use is the official journal of the World Society for Transport and Land Use (WSTLUR) and is published and sponsored by the University of Minnesota Center for Transportation Studies. 
All of these factors have the potential to reshape our urban and suburban areas but they are also subject to innovation and disruption, particularly as trip needs and energy demands change. Research is showing that new mobility / mobility-on-demand services not only increase travel but have the potential to increase vehicle miles traveled (VMT) and the total number of trip-a trend even evident during the COVID-19 pandemic (Gehrke et al. 2019; Riggs 2020). They also may not address roadway capacity issues and integration with the logistics network as efficiently as transit, walking or cycling solutions.

In this context, this paper focuses on the concept of "minimobility" as a new segment for urban transit, particularly aimed at increasing roadway capacity in cities, and increasing VMT without the greenhouse gas (GHG) emissions penalty. What is minimobility? Simply put, minimobility is an attempt to classify small vehicles larger than a bike or scooter and smaller than a car or shuttle that are largely e-powered. As illustrated in Figure 1, it is the solution between micro (kick bikes, bikes, motorbikes) and regular (cars) mobility options.

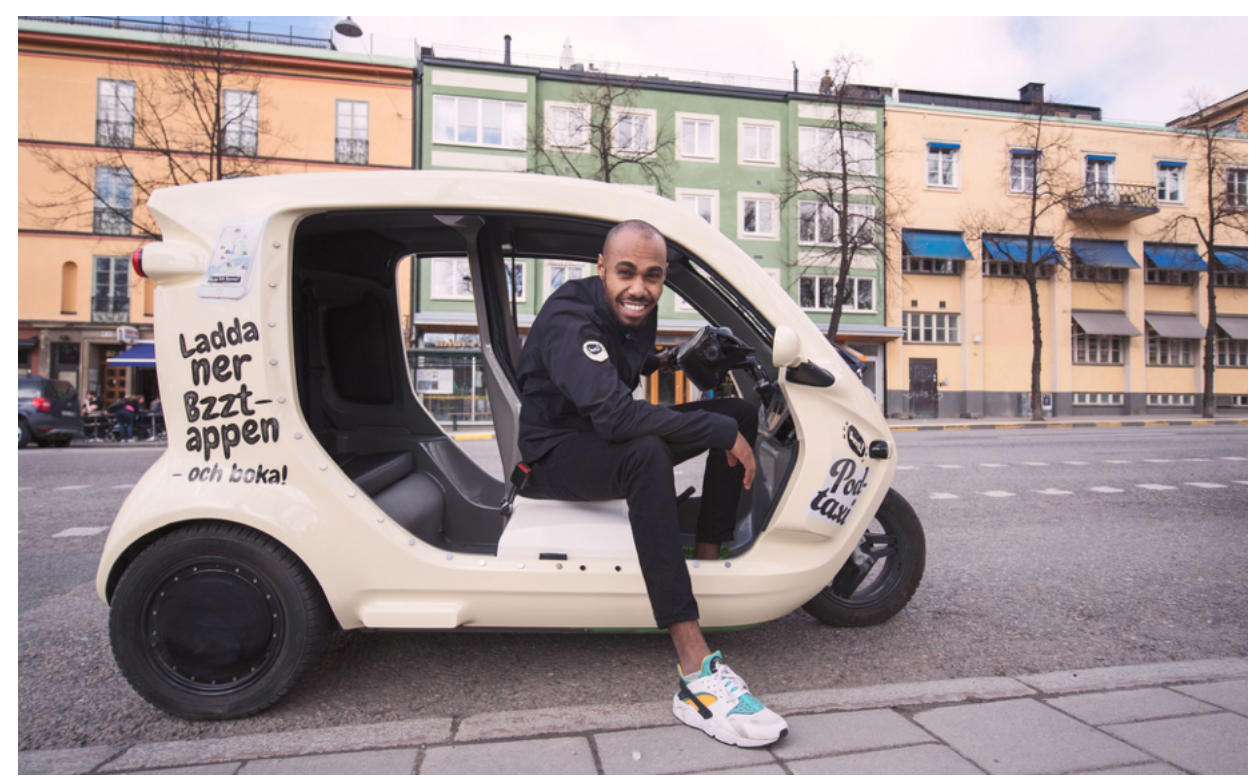

Figure 1: The Bzzt Minimobility Platform

Researchers have long attempted to define travel modes and their characteristics; classifying business models for mobility. Local passenger transport modes can be categorized as being 'common carrier' (user rents a seat/space), 'paratransit' (user rents the vehicle), or 'private' (where the user owns the vehicle), with each type of carrier having advantages(Vuchic 2007). As this idea of the 'common carrier' has evolved it has begun to include other forms of urban transportation and shared mobility services such as car-sharing, bike-sharing, ride-sharing, on-demand ride services, and microtransit. Likewise experts have defined these segments by how they present distinctive opportunities of platform and place (Riggs and Beiker 2020).

Minimobility meets these thresholds and can be considered one of these separate segments. In one extreme end of the range, a minimobility vehicle could be made for a driver and one passenger to fit on normal bike lanes-something that overlaps with micromobility vehicles, yet is set apart. On the other end, there could be no drivers and multiple passengers with an opportunity to fit many more small vehicles in the same right of way. While this overlaps with micromobility from a place-based sense, the minimobility platform has different physical features that make it a separate segment of the transportation market; both as a 'common carrier' as well as both a Mobility-as-a-Service (MaaS) and logistics provider. 
The goal of this paper is to explore minimobility (e.g., very small platform transit) using the case of the Bzzt platform in Stockholm. We position this work to evaluate the economic and operational feasibility of a business that uses a specific technology that has not been widely deployed elsewhere using a shared service. We believe that it is import to research illustrate the cost-effectiveness and operational / financial viability of such a modal platforms in attracting riders and drivers, explore offering competitive price options to the consumers as well as pursuing the benefits of a reduced GHG. While it is beyond the scope of the data in this case assessment to apply this work to other locations it is probable that the built environment in places like New York, San Francisco, Chicago or many compact college campuses could be conducive to similar deployments as have been used in Stockholm.

The paper begins with a brief background on emerging transportation trends, including an increased focus on the 3E's of sustainable transportation: economy; environment; and equity. We then describe and look at the case of Bzzt in Stockholm to assess the benefits of how minimobility can potentially help cities pivot away from GHG emissions without sacrificing the economic benefits of highly connected and accessible downtowns. Finally, we dialogue this analysis and provide a discussion of potential policy implications and opportunities for further analysis.

\section{Background}

A growing body of research has focused on technological disruptions to the transportation market (Riggs 2018). Advances in technology, business models, commercialization, funding and policies have dramatically changed the way people in cities access and use transportation. Clearly, there is considerable scope for further developments to realize productivity improvements while creating more sustainable environments in our cities and at the same time harness the value of these new innovations (Sperling 2018). Research has shown that these diverse modes of transportation have the potential to facilitate increased accessibility and improve efficient transportation systems, but also potentially worsen traffic and congestion, pulling individuals away from transit and other sustainable modes of travel.

Ridesharing services, also known as Transportation Network Companies (TNCs), have been one of the primary disruptors in this space in recent years. Driven by changes in demographics and lifestyle preferences, users are relying on privately owned vehicles and less transit while engaging in more travel as a whole (Clewlow and Mishra 2017; Gehrke et al. 2019). Most users of ridesharing services expect environmental benefits, yet are variety seeking and may/may not be heavily reliant on transit-craving convenience and reliability in their mobility option (Alemi et al. 2018; Circella and Alemi 2018; Harb et al. 2018). Many services are in-effect merging into MaaS platforms combining various transportation options into single seamless offerings that are made available to users via subscription-based applications (Beutel et al. 2014; Goldman and Gorham 2006; Sochor et al. 2015).

\subsection{Continued Mobility Innovations}

It is important to consider that new disruptive trends in transportation are not static. As the 2018 popularization of e-scooting indicated, the trends are continually evolving and with the growth in population in urban centers leading increased land use, there is more pressure on the reliability of transportation systems (Noland and Polak 2002). Traditionally, the focus has been on minimizing congestion and commute times only to realize that single occupancy vehicles exacerbated congestion, health issues, and increased environmental contamination (Pucher and Dijkstra 2003). Policy makers now promote the idea of optimal congestion as opposed to minimal congestion that is arguably more sustainable (Banister 2008; Lyons and Urry 2005). The modal shift from single occupancy vehicles to walking, public transit and/or shared transit alternatives was aimed to reduce trips and increase travel efficiency. 
As "subtractive" services, both taxis and ridesharing were expected to reduce the overall VMT by encouraging shared rides, supplementing transit systems by multimodal trips and eliminating wasteful driving like when looking for parking (Anderson 2014). Whether there is empirical evidence of this reduction is a question that needs to get answered. For example a study from a survey of 416 rideshare users estimate that these services led to an approximate 84\% increase in VMT than if rideshare had not existed (Henao and Marshall 2018). Further Schaller (2018) says that TNCs added 5.7 billion miles of driving in US's nine largest metro areas (including, but not limited to, NYC, Boston, Chicago, LA, and $\mathrm{SF}$ ) at the same time car ownership grew more rapidly than the population. It further adds that TNCs put 2.6 new TNC vehicle miles on the road for each mile of personal driving removed. It is interesting to note that ridesharing as a mode does not seem to be competing with personal autos on the core mode-choices of speed, convenience and comfort. Also, the fact that ridesharing is a valuable extension of public transit is undeniable. Not only can these services be used when the public transit is infrequent/non-existent but they can also provide effective reach to outer suburbia where public transit might not have a grasp.

\subsection{The Pivot to Reduced Emissions GHG in Travel}

Evidently, while rideshare might encourage connectivity, it might also be contributing to congestion and GHG emissions. Appleyard and Riggs (2018) and Riggs et al. (2019a) present a framework for achieving the goals of sustainability, livability and equity in an electric automated vehicle future by using fewer cars through greater sharing, traveling shorter distances, and at lower speeds. It is argued that the advent of electric autonomous or non-autonomous vehicles might alleviate some of the environmental concerns. In the past few years a new momentum for battery electric vehicles, hybrid electric vehicles and hydrogen fuel cell vehicles has emerged. Innovations in this area has eased the deployment of hybrid vehicles (the Toyota Prius being a prolific example) at scale. For mobility providers or operators that include car sharing and carpooling services wherein the underlying business model is that of collaborative consumption, battery electric vehicles are attractive because of low operating costs that compensate for higher purchase prices.

Dijk et al. (2013) explain that the future of mobility powered by electric vehicles would depend on developments in infrastructure, mobility in general, global car manufacturing regime, energy prices, and electricity sector. The addition of electric vehicles into the mix might create a need to share this resource in a creative way. The potential sustainability benefits of sharing vehicles can be pivotal from organizational and environmental perspectives (Cohen and Kietzmann 2014). If the vehicles being driven are electric, then the benefits will likely proliferate. According to Hansen et al. (2009), numerous factors in urban areas support the introduction of sustainability-oriented innovations including: market imperfections (Cohen and Winn 2007); and demand from consumer, corporate and government stakeholders (Hart et al. 1997).

Mobility services are seen as a way to shift toward a future that has sustainable transportation systems that ensure better urban management, choices of modes for travel that can be combined in more ways, energy efficiency that leads to better air quality and is cost effective for the consumers, electric vehicles that limit the usage of renewable fuels, and an optimal travel experience (Greenblatt and Saxena 2015; Greenblatt and Shaheen 2015). The success of a shared economy has been driven by growing environmental consciousness mixed with the ubiquity of wireless and mobile technology that have made sharing possible at a large scale (Cohen and Kietzmann 2014). Public companies like Dutch Railway Company NS has transformed itself into a mobility company that offers public bikes at a low cost to train travelers and issues a mobility card with integrated billing services. OV-fiets is a bikeshare system that is aimed for the last mile (Küster and Lancaster 2013). With over 300 rental locations in the Netherlands, the service is successful in delivering on its claims.

E-bikes/bikeshare and e-scooters constitute another area of innovation in mobility options (called micromobility) that have been operating successfully on a standalone basis. The penetration of bike- 
share programs in cities and suburbs across the world is noteworthy. Yet, the ultimate goal of bikesharing, as argued by Shaheen et al. (2010), is to expand and integrate cycling into the overall transportation system as a daily transportation mode. However, multiple factors affect the viability of bikes as a regular mode choice. Even in the presence of an extensive bike conducive environment and supportive infrastructure, riders must be willing to physically operate bikes. Yet, bike trips tend to be shorter than motor vehicle trips (MacArthur et al. 2014) but distance barriers can be addressed by e-bikes that can ensure wider adoption. E-scooters fall into the same category. For distances under five miles (CB Insights 2019), both e-bikes and e-scooters are effective modes. In addition to passenger transport, Intelligent Energy Europe program has assessed the potentialities of electric bikes and scooters for delivering goods and services in urban areas as an alternative to combustion engine vehicles. Nocerino et al. (2016) provides an exhaustive account of the Pro-E-Bike project that started in April 2013 and ended in March 2016.

\subsection{Distinguishing minimobility}

On combining many of the traditional modes of transportation and the innovations discussed above, minimobility can be defined by the following characteristics, even if the border lines are grey zones.

- Vehicles are optimized to do the job of transporting people short to medium distances (1-10 $\mathrm{km}$ ) in city traffic (meaning top speeds of maximum $50 \mathrm{~km} / \mathrm{h}$, often $40 \mathrm{~km} / \mathrm{h}$ ) with sufficient comfort and safety but with limited amount of baggage. (Less baggage space than regular cars but more than micromobility.)

- Vehicles are minimalistic and compact. They can be light and simple and still do the same transport job as a 4500-pound car in these conditions ( $800 \mathrm{lbs}$ for 2 passengers, $1000 \mathrm{lbs}$ for 4 passengers, and 1400 for 6 ). The vehicle can house a driver and up to 6 passengers. The driver could be a human or a machine.

- Cost per ride is significantly less than alternative ride service, and only marginally more than public transit for 1 passenger, less for 2 passengers and more.

- Safety of the driver and the passengers is ensured by them being secured to the vehicle with safety belts and protected by the its structure, as opposed to helmets and gears recommended for micro-mobility options.

- They are neutral or entirely emission free.

- Vehicles are deployable in urban conditions to support other forms of transit and walking.

\section{Methodology}

Given this background, the goal of this paper is to evaluate the potential benefits of minimobility in cities. Potential benefits including optimization and efficiency of the transportation network and reduced emissions as well as increased access for those who want to travel further (for example 5 to 10 kilometers) but would be disinclined to do. This distance is a little too long and time-consuming to walk, a little too short to efficiently find and use public transport means, and too expensive for regular taxi or ride hail. Micromobility options might be suitable for certain populations, but they are not accessible to those with reduced capacity and may not appeal to the traveler who wants to be safe and weather protected particularly in inclement weather conditions.

\subsection{The Case of Bzzt Stockholm}

We use the case of Bzzt Stockholm, in two data snapshots: 1) first an evaluation of emissions using a greenhouse gas climate model; and 2) then an evaluation of user data over a six-month period evaluating the cost, operational performance as well as response time for the app-based service. The duration, we believe, is enough to provide a sense of their operations and given that their zone of business was 
limited to downtown Stockholm. We have not incorporated the 2020 data since it wouldn't be indicative of normal operations.

The data provided to us for evaluating the financial performance had the following fields: (i) The entire route of a trip with stops made along the way, (ii) cost of the trip, (iii) distance traveled in kilometers, (iv) date and time of the trip (timestamps), (v) names and other identifiers of the consumers. We have not used any possible identifiers for secuirty reasons.

Bzzt (https://www.bzzt.se/) is a "pod-taxi" minimobilty service currently operating in Stockholm, Sweden. The company provides an app-based taxi service in urban areas, at the price point that is targeting that of public transport and with zero local emissions. All the taxi pods in the fleet are Light Electrical Vehicles and the fleet operation is optimized with an in-house software. In as much, the fleet could have the capacity to serve as a flexible and low emission alternative for last mile urban deliveries. The company has had commercial customers since May 2017. They focus on last mile transport and intend to add last mile urban freight deliveries to the platform to increase efficiency and profitability further.

The Bzzt app has been downloaded by every 5 th person in Stockholm with $90 \%$ of trips done by recurring customers. The system operates in central Stockholm and has delivered close to 200,000 trips since their launch in spring 2017, utilizing the 50 pods in operation. An average trip is $2.17 \mathrm{~km}$. Consistent with the minimobility definition, vehicles are light weight (600 pounds) and emission free and take up one-third of the space of a regular car. Bzzt manages and optimizes the operation of the fleet of vehicles and drivers, meaning: full digitalization of all (support) systems (booking, fleet management, people management); making all entities online (vehicle position, garage/charging depot status, battery state of charge, driver status, charger station status to mention a few key entities); moving toward Artificial Intelligence/Machine Learning for predictions and related decision-making considering hundreds of data streams from the city. They use a simple and transparent distance-based price model, currently "0.04 SEK per meter" and employ all drivers under a specific union agreement.

\subsection{Emission Methodology}

To calculate the emissions footprint of the Bzzt platform, a sample of 219 Bzzt passengers were surveyed about their primary mode of transport had they not taken the minimobility option. The potential emissions for that mode were calculated, with avoided emissions calculated by applying the potential emissions reduction per passenger transport or kilometer per market segment. The potential emissions reduction within the passenger transport segment was calculated by comparing a weighted average emission of alternative transportation modes with the solutions' emissions, production of the respective vehicles excluded. Based on the UN Sustainable Development Goals this was consistent with the definition of the passenger transport market defined as trips shorter than five kilometers carried out by the global population in cities larger than half a million inhabitants, and based on transport habits of the urban population in the relevant city.

\subsection{Cost and Operational Performance}

To give a glimpse of the steadily growing operations of Bzzt, a time and cost-based analysis of its demand for the months January through June 2019 was conducted. The goal was to demonstrate the financial viability and economic benefits of minimobility as a concept. Clearly, operations have a relationship to the environmental implications of any mobility option, yet we dealt with them separately. While we were able to calculate the emissions of a trip using the distance travelled, the approach was limited in that we were unable to capture full congestion emissions and traffic data in downtown Stockholm for the six-month period of evaluation. Our operational analysis was based on the company's operational data that contained the following fields for approximately 57,900 trips during the six-month period: Pickup and drop-off locations and times, routes with time stamps, trip costs, and time durations among a few. 
- Based on the information on the pickup location, date and time, an unsupervised learning method, k-means was used to form clusters. k-means clustering is a method for quantization of vectors that, when applied to the context of data analytics, tends to find clusters of comparable spatial extent.

- The method partitions the observations into $k$ clusters in which the assignment was based on the proximity of an observation to the mean/centroid of a particular cluster.

- The algorithm was limited in the sense that the number of clusters $k$ need to be specified. Normally, in geospatial analysis, the segmentation may be obvious. However, in cases where it isn't The Elbow Method is employed. It is used for interpolation and validation of consistency within clusters. By arriving at the percentage of variance explained as a function of the number of clusters, it helps in arriving at an optimum number of clusters in which a dataset should be divided.

- Spatial visualizations were created by using Static Google Maps API and ggmaps (Kahle and Wickham 2013). To deal with overplotting, 2D kernel density estimation was performed. The results are presented in the following section.

- The data used throughout this paper was meant to provide an indicative picture. It is in no way to be treated as an exhaustive depiction of Bzzt's operations. Further, Bzzt Stockholm was in early phases of its business during our period of evaluation. Their scale and pattern of operations may grow substantially over the coming years.

\section{Results}

\subsection{Environmental Implications}

As Bzzt vehicles are optimized for urban transport, the environmental benefits compared to current regular cars are revealing. Minimobility vehicles are lower mass than private autos and need approximately $1 / 3$ of the material mass for production. This results in substantially lower energy consumption compared to other modes. The average electric car consumes average electric car consumes approximately $0.20 \mathrm{kWh} / \mathrm{km}$ while the Bzzt minimum platform consumes less than half of that at 0.09 $\mathrm{kWh} / \mathrm{km}$. A standard Bzzt pod uses approximately $15 \%$ of the energy of a modern Volvo V70 diesel and emissions can be improved based on the renewable energy of electricity.

\begin{tabular}{|c|c|c|c|c|}
\hline \hline Alternative & Number & Percent & Emission (kg CO2e/trip) & Weighted Emissions (kg CO2e/trip) \\
\hline \hline Bus & 47 & $21 \%$ & 0.2500 & 0.0537 \\
\hline Taxi & 69 & $32 \%$ & 0.7670 & 0.2417 \\
\hline Bike & 11 & $5 \%$ & 0.0000 & 0.0000 \\
\hline Subway & 27 & $12 \%$ & 0.1599 & 0.0197 \\
\hline Walk & 54 & $25 \%$ & 0.0000 & 0.0000 \\
\hline Car & 10 & $5 \%$ & 0.6712 & 0.0306 \\
\hline Other & 1 & $0 \%$ & 0.0000 & 0.0000 \\
\hline \hline & 219 & $100 \%$ & & 0.1822 \\
\hline Bzzt & NA & NA & 0.1822 & \\
\hline
\end{tabular}

Table 1: Emissions of Bzzt Passengers Substituted Mode (N=219)

As illustrated in Table 1, based on the Stockholm case this yields substantive reductions in emissions compared with traditional fossil fuel based vehicles and with other modes, including transit. The service outperforms all other transportation services but walking and cycling in terms of emissions on a per $\mathrm{kg}$ / trip basis. When calculating the emissions based on percent volume (since very few individuals drive in central Stockholm and $42 \%$ of individuals walk, bike or take the subway) the platform out-performs the competition on a per-trip basis. 
Particularly when comparing the Bzzt platform to traditional taxi services, the service reduces emissions over $100 \%$ providing greener, on demand transportation by harnessing the lesson from ridesharing services. Taxis emit $0.2417 \mathrm{CO} 2 \mathrm{e}$ per trip when considering the percent volume of users while Bzzt platforms use $0.1822 \mathrm{CO} 2 \mathrm{e}$ per trip. This illustrates that the service can play a complimentary role in improving trip efficiency and effectiveness along with reducing emissions.

\subsection{Costs and Operational Performance}

\subsubsection{Demand Patterns}

Related to the potential of this environmental footprint, it is clear that the concept can be scaled based on demand to maximize impact. Some estimates show that, at scale, the mini mobility concept could have $30 \%$ market share of trips shorter than $5 \mathrm{~km}$ in large cities by 2030 and totally reduce $64 \mathrm{M}$ tons CO2e annually (Hennessy 2019). To estimate the level and geographic spread of Bzzt's demand in the Stockholm area, we used a heatmap to factor in coverage and the spread of demand.

The city center area of Stockholm is divided into four major districts: (i) Kungsholmen, (ii) Norrmalm, (iii) Södermalm, and (iv) Östermalm. Evidently, the pickup activity in districts (ii) and (iv) is the heaviest for Bzzt as per the heatmap. The dominant purple spot on the heatmap is Stureplan, which is a common meeting spot for the city and is also a prominent area for nightlife. It is critical to note that Figure 2 is produced after $2 \mathrm{D}$ kernel density estimation. We also wanted to explore a more detailed street-wise spread of the demand.
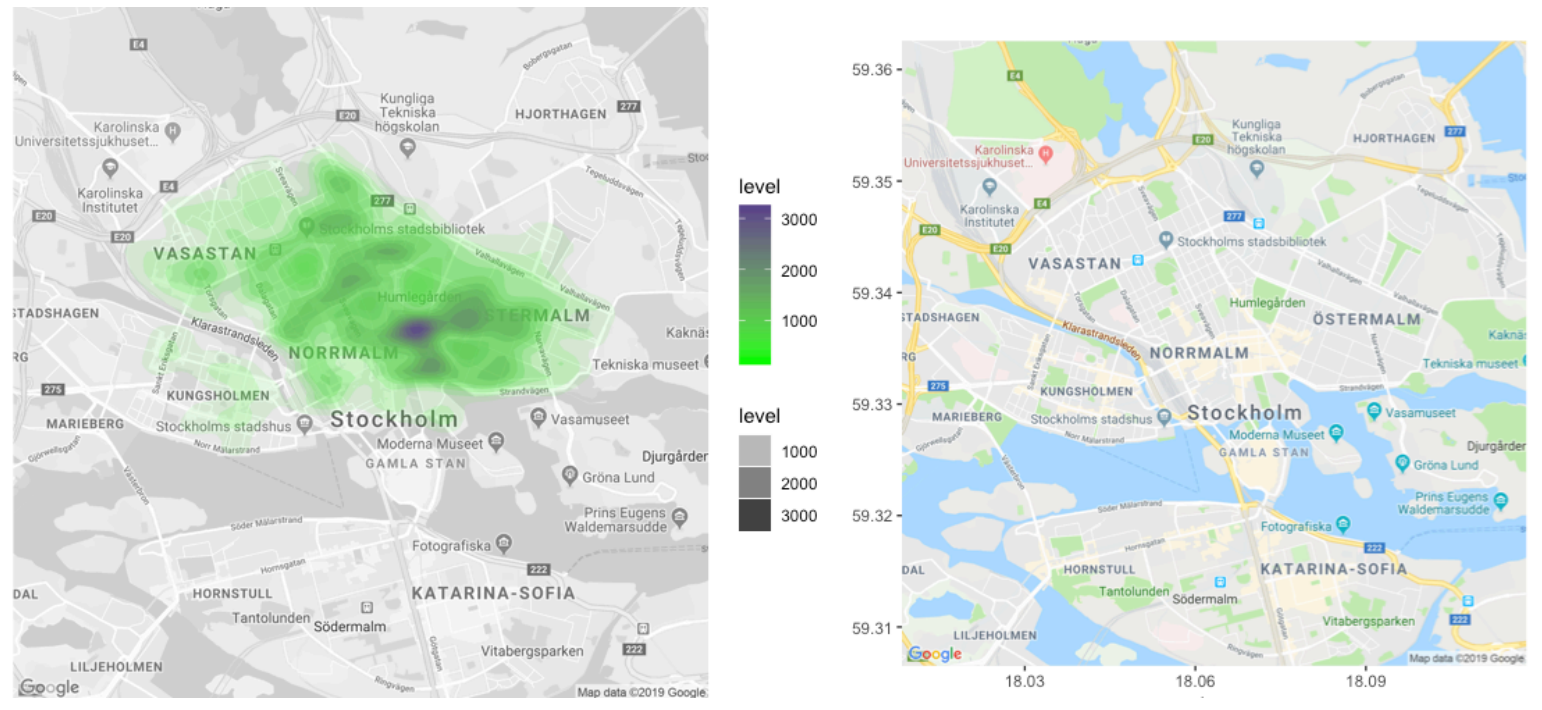

Figure 2: Comparison of the Pickups (left) with the 4 Districts of Stockholm City Center

As illustrated in Figure 3, we observe that Bzzt has a presence in Norrmalm, Kungsholmen, and Östermalm. The Elbow Method reveals that the observations could be bifurcated into three main clusters which coincides with the activity in the three districts as mentioned above. Red in Figure 2 is assigned to cluster 1 corresponding with Kungsholmen, green is for the second cluster of Norrmalm, and blue for Östermalm. On the $\mathrm{x}$ and $\mathrm{y}$ axis, there are longitudes and latitudes, respectively.

Clearly, as Figure 3 shows, there are pickups on almost every street/road of the three districts. There is also some activity along the Gamla Stan area. Bzzt does not pick up customers from outside their current zone of business. Otherwise, the requests would be more frequent than observed in Figure 3. There are pickups requested from neighboring districts as well.

Using these clusters, we further explore the demand behavior based on the hour of the day and the day of the week. Following are the results. 


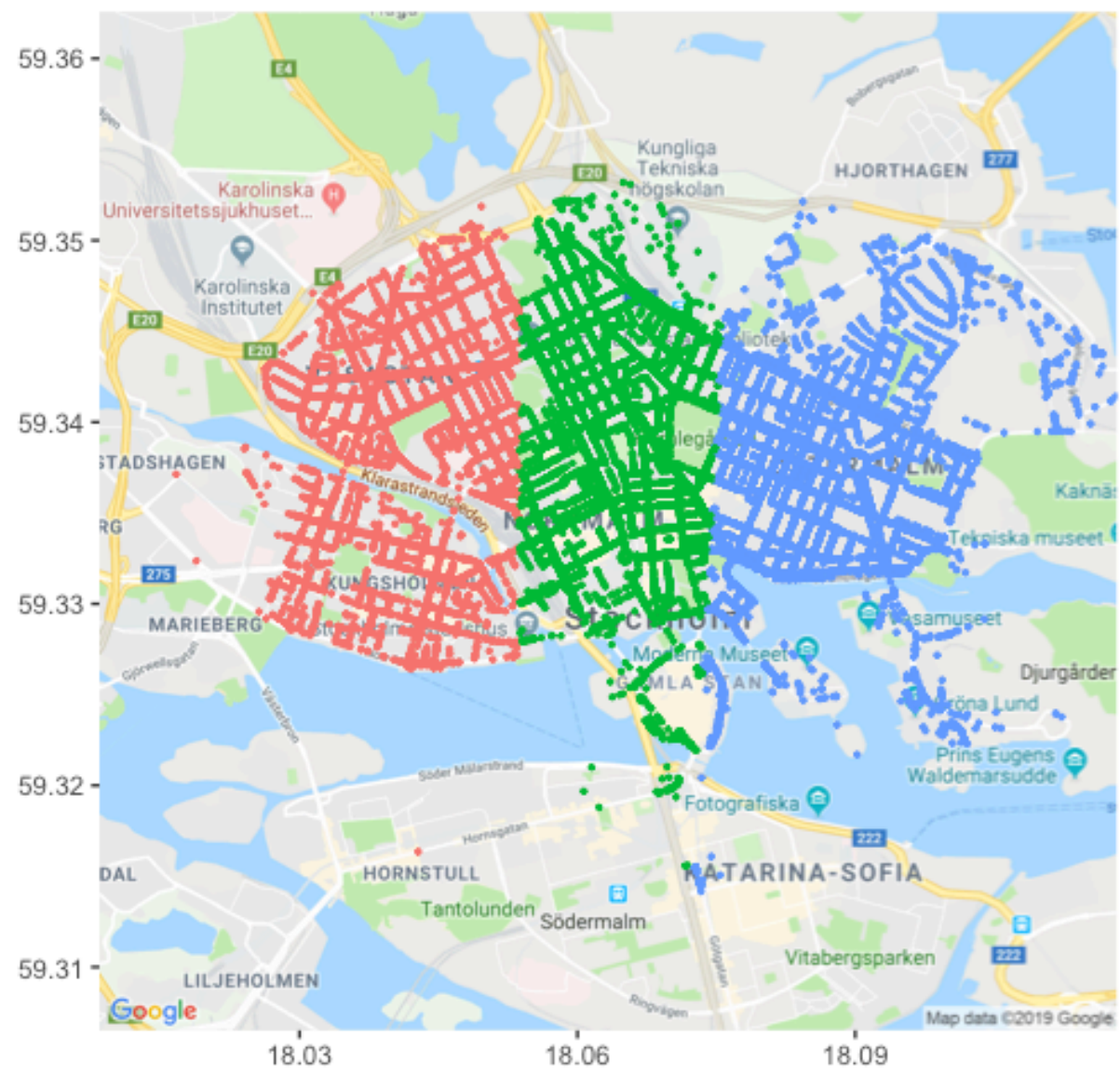

Figure 3: Clustering of Pickups

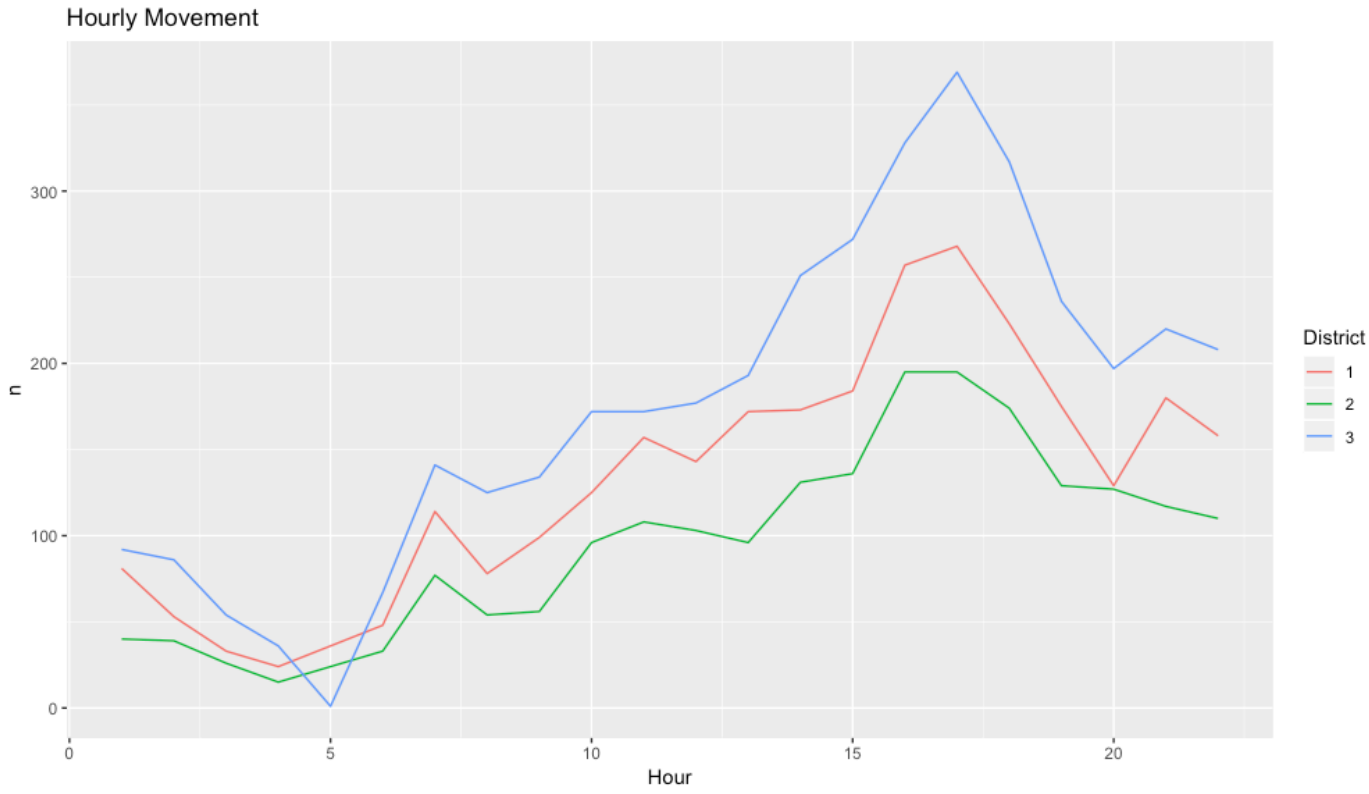

Figure 4: Average Hourly Demand 


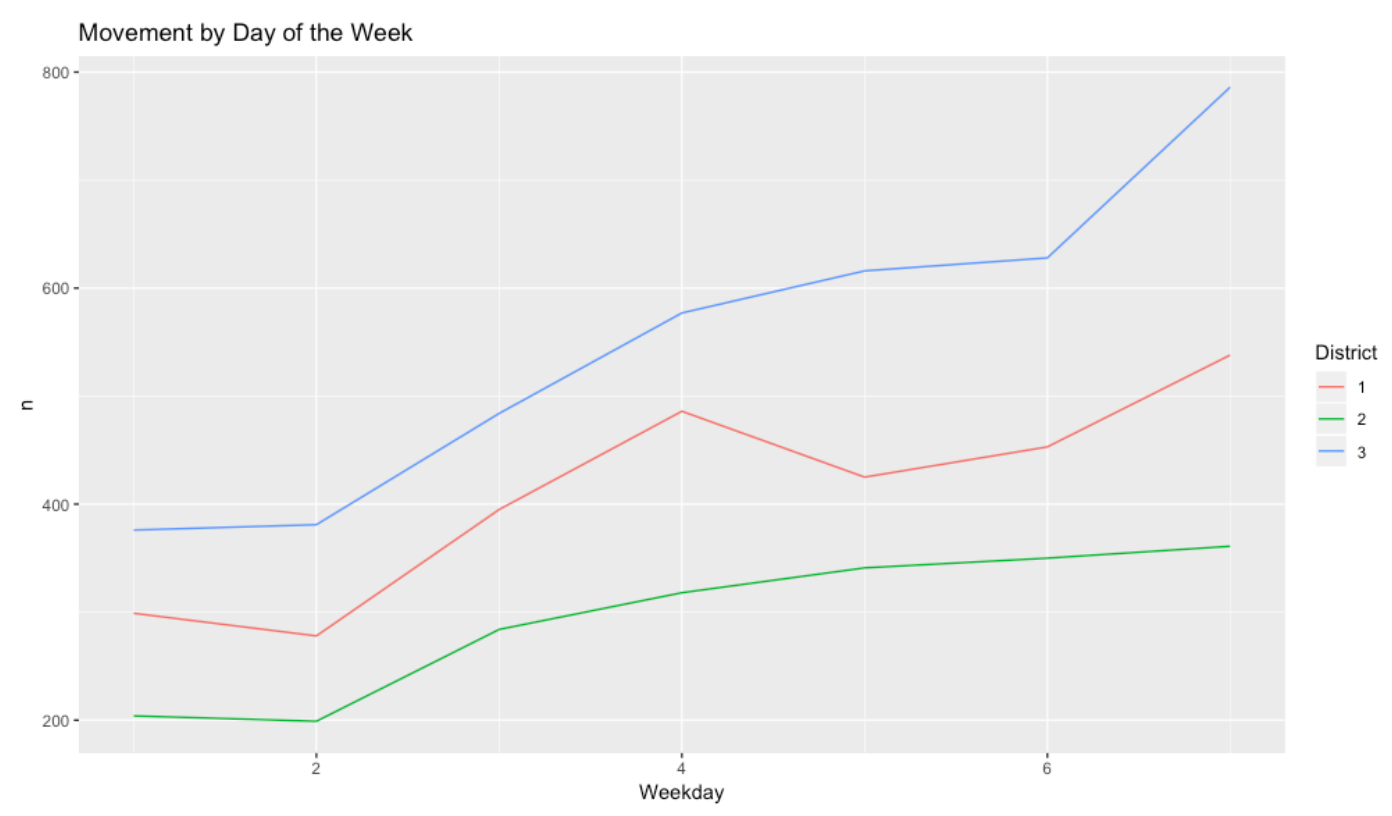

Figure 5: Average Daily Demand

Here, District 1 is Norrmalm, 2 is Östermalm and 3 is Kungsholmen. In Figure 4, the hourly pattern indicates that there is a spike in demand between 5:00 a.m. and 7:30 a.m. after which there is a steady increase before it peaks again between 3:00 p.m. and 5:30 p.m.. A quick decline is observed after that time. This hourly movement occurs across all days of a typical week. It is representative of months April through June. For the same three months, Figure 5 shows the behavior of demand every day of the week. Our hypothesis based on these day-time trends proves that the service is used for regular, work-related trips as well and not just recreationally.

When looking at weekends with more granularity (Day 1 is Sunday and Day 7 is Saturday) two peaks in demand emerge over the week. They are shown in Figure 5. One of the peaks is on Wednesday (hours of operation: 7 a.m. to midnight) and another on Saturday (10 a.m. to 4 a.m.). Given that through Figure 2 we had already established that the captive population (Bzzt does not collect age related information for privacy purposes) concentrates the demand around the city center area where nightlife is prominent and is generally a meeting spot, there is a sharp increase in demand around Saturday.

In the legend, 1 signifies weekday and 0 signifies weekend (Saturday and Sunday). While the cumulative demand during weekdays is higher, also because of there are more number of days falling into that category, the patterns of behavior on weekdays and weekends are similar. Between midnight and 2:30 a.m., the demand on weekends is significantly higher during weekends since the hours of operation on Saturday are 10 a.m. to 4 a.m. (the next day) and on Sunday are 10 a.m. to midnight. On weekends, however, the operations end around midnight with the exception of Friday wherein they spill over to wee hours of Saturday. The morning (5:00 a.m. to 7:30 a.m.) evening peaks (3:00 p.m. to 5:30 p.m.) in demand are clearly more prominent during the weekdays. There is a general increase in travel starting 5:00 p.m. until 5:00 a.m. during weekends.

\subsubsection{Cost and Time Analysis}

The financial operations of the system appear to be quite stable. Of the three prominent regions of operation, Norrmalm consistently records around $43 \%$ of the total business the company has in Stockholm. Of the total demand fulfilled each month, the district accounted for its lowest of $42.49 \%$ in January to the highest of $44.18 \%$ in March. Östermalm comes in second with an average contribution 


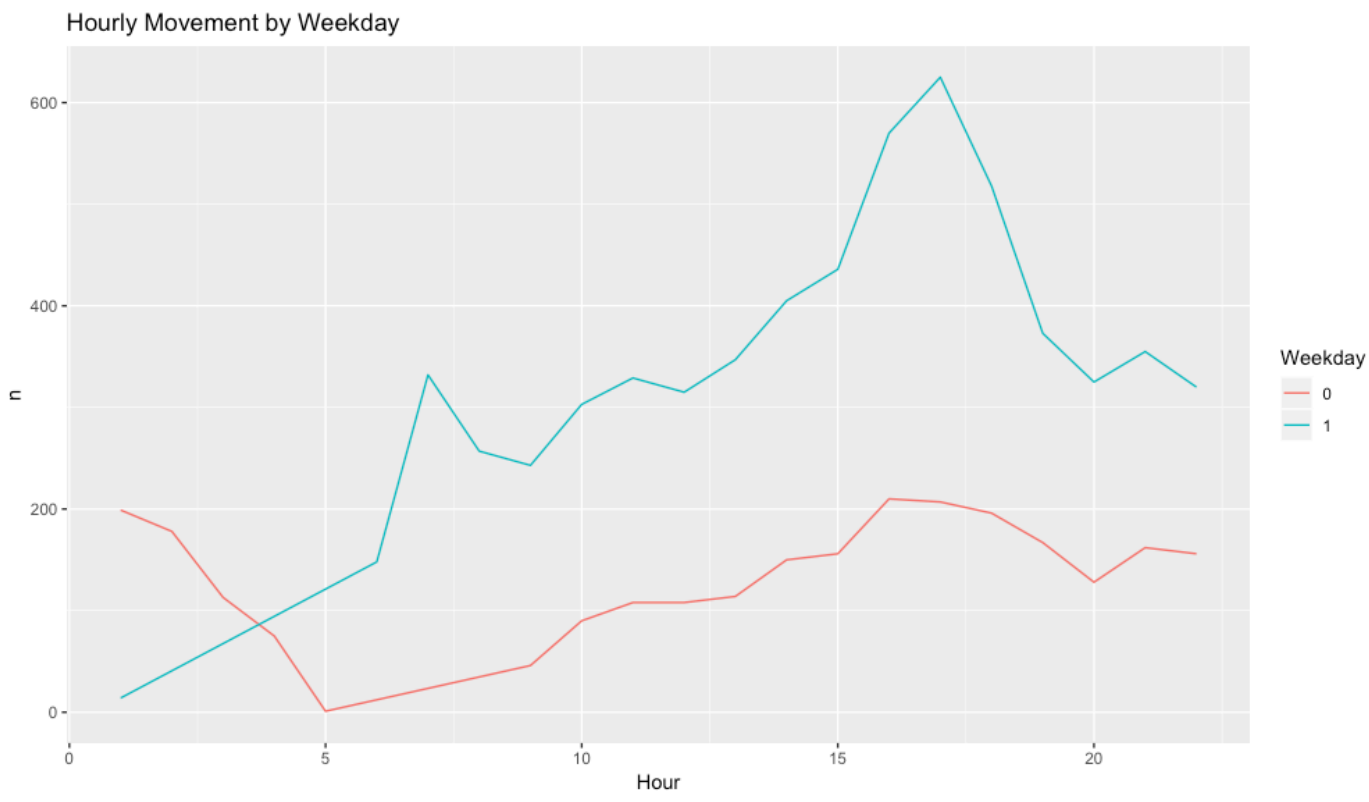

Figure 6: Average Demand by Hour bifurcated into Weekdays and Weekends

of $33 \%$ in the overall, with its lowest of $31.23 \%$ in February and the highest of $33.36 \%$ in May. For both districts the demand contribution does not vary significantly.

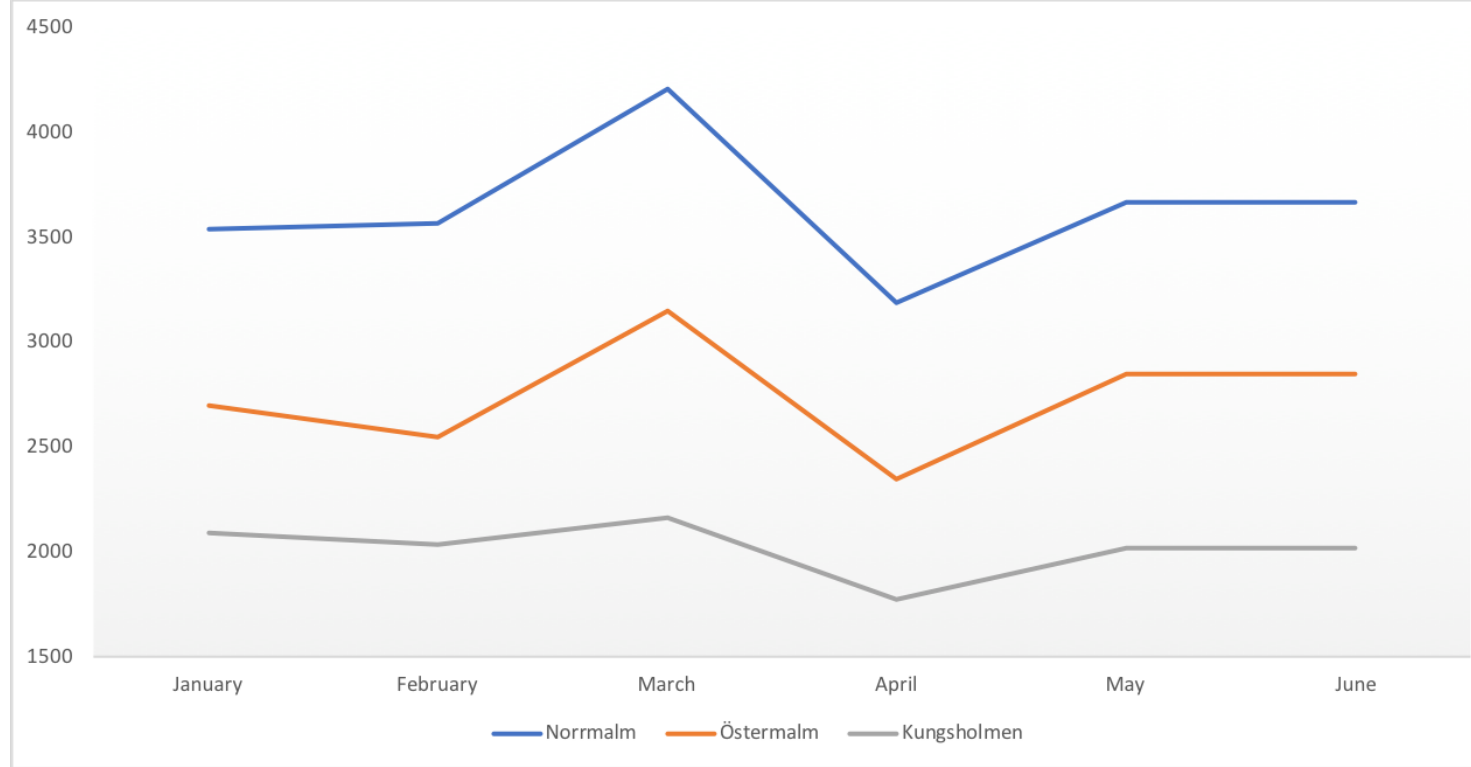

Figure 7: Monthly Breakdown of Demand by District

Demand had grown in March but the advent of e-scooters, launched on a large scale in Stockholm, appears to have led to the sharp decline in usage in April. However, the operations returned to as they were during January and February which is a promising sign and speaks for the preference of the service among the population. Bzzt expects that the shift from those micromobility options to minimobility will follow when the weather conditions turn more favorable during fall.

The above shows the difference between the actual time of pickup and dropoff for each month. There is a steady increase in the average trip duration which can be attributed to the worsening traffic conditions, especially in a region like the center of the city. The company, on an average, in $82 \%$ of its 


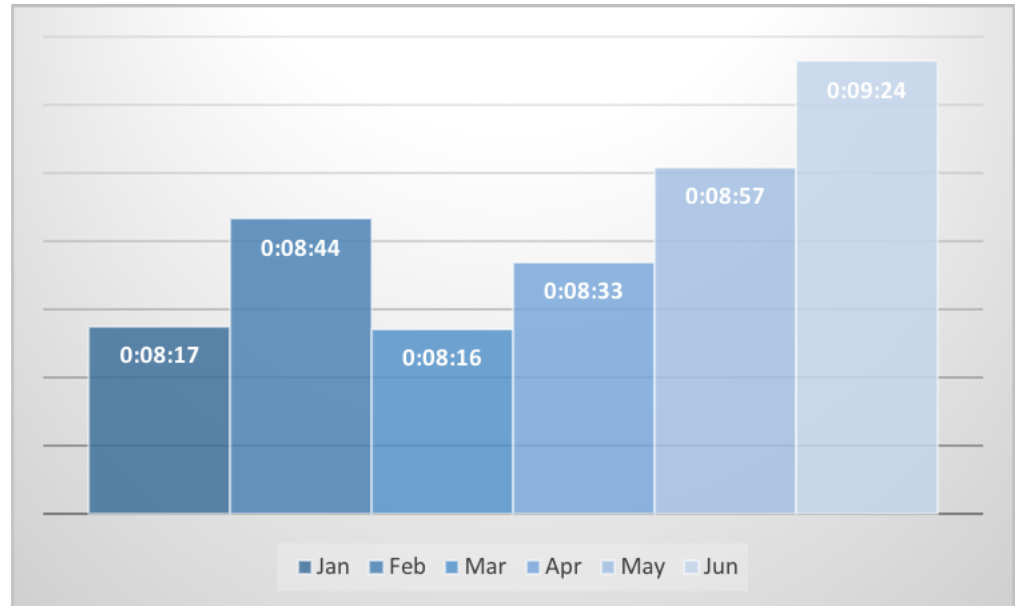

Figure 8: Average Trip Durations by Month

trips in the past six months has witnessed higher actual trip durations than the estimates it provided to its users. Another reason is the growing average of the distance traveled.

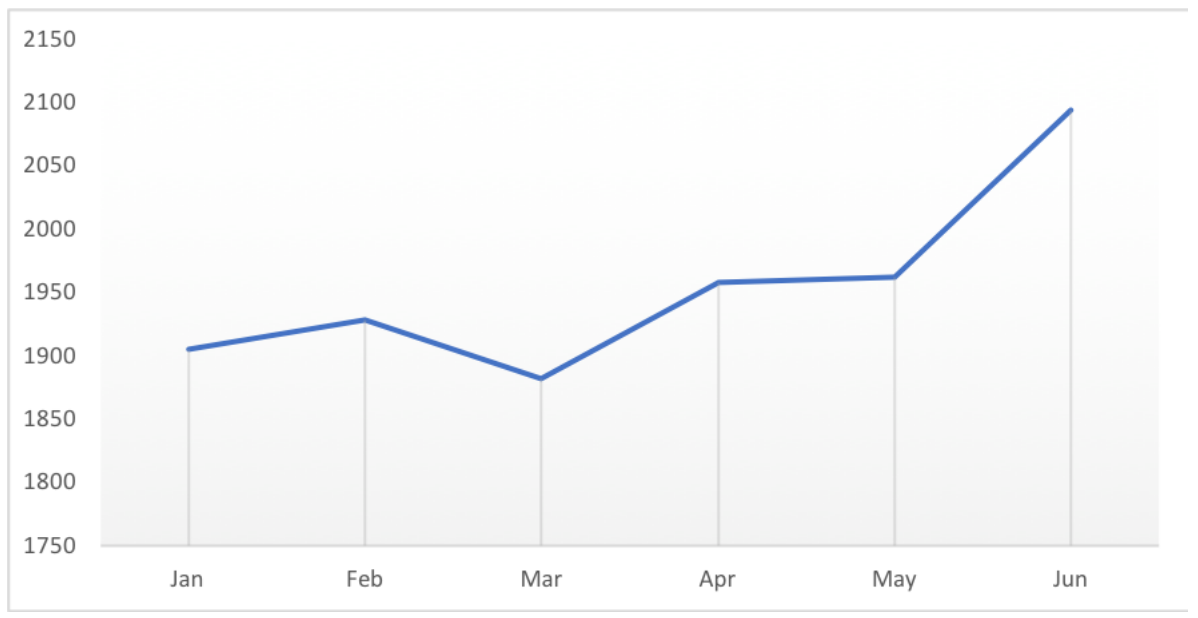

Figure 9: Average Distance Traveled in Meters

After March, there seems to be a rather steady growth in the average meters traveled by the users. Aside from the various measures of Bzzt that are underway to improve congestion estimations, there are bound to be adjustments made by drivers during trips. It also goes to show that the users might be starting to prefer the Bzzt pods for slightly longer trips. We expect this to plateau soon given that this mobility option fills the gap between micromobility options like bikes and scooters that move slower and transit options that are preferred for much longer distances.

Responsiveness of users is also evident from the average time lapse between when the ride was requested to when it was accepted. The average duration of acceptance is only approximately 6 seconds. This goes to show the efficiency of Bzzt's network since the drivers are assigned to the riders rather quickly. Between March and April the users saw a 33\% increase in the per meter cost; from 0.03 SEK per meter to 0.04 SEK per meter. Bzzt has a stable and dedicated user base that continues to use their services as is clear from Figure 9.

The average costs of trips are on the rise since March, primarily due to the price increase and secondarily due to the increase in the distances traveled. It is important to note that as per Figure 7 , the monthly demand is more or less steady. This could be indicative of the users being price insensitive to 


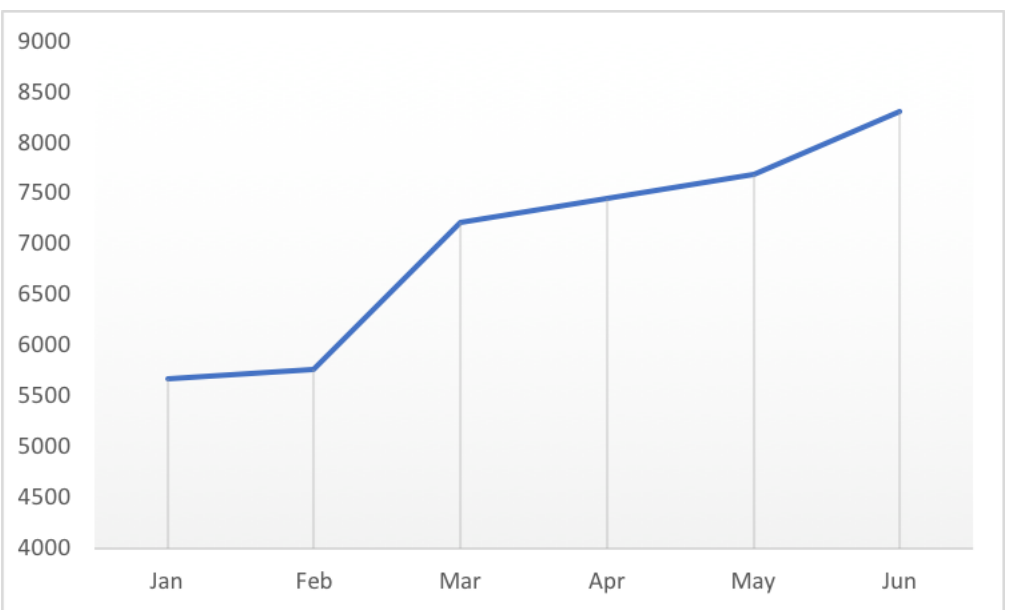

Figure 10: Growth in Average Cost of Trips

the service Bzzt provides. Another reason for customer satisfaction can be that in roughly $68 \%$ of the trips each month, the actual cost turned out to be lower than the estimated costs.

\section{Discussion}

As the data shows, consistent with other work showing how new mobility expands the transport marketplace, the increase in rides can be achieved without additional GHG. Due primarily to the EV minimobility platform, we see a general increase in VMT, that is not coupled with an increase in GHG. Our analysis indicates that the average energy consumption of a minimobility trip, including the drive to pick up the customer, is $0.3 \mathrm{kWh}$ (yearly average including energy for heating and support systems), and that in terms of the per-ride emissions, this exceeds the carbon footprint of any form of transport, but walking, cycling or subway.

At the same time this is not a zero-sum equation. At a systems level, walking, cycling and transit still perform more highly from an GHG emissions reduction standpoint. In certain locations in Stockholm, car ownership is low and walking and cycling is still optimal over driving and transit. Yet beyond those locations, the market for services like Bzzt gains great efficacy; particularly where traditional, as opposed to on-demand and smaller platform services, are more effective. This reflects the same service dynamic seen in many global cities and the admissions of experts like Robert Cervero (2017) who has lamented that since, "Transit rarely delivers customers near the doorstep of where they're heading, it is not surprising that more than 90 percent of motorized trips by Americans are by private car." This dynamic also reflects the service differences between dense urban downtowns that are served by high density rail or BRT service and the suburbs where transit accessibility lags. It also a huge opportunity to increase total access to mobility-particularly if this can be done in low-emitting fashion. And if societal goals are aligned to pursue a zero-emission transportation future, then it is likely that these types of services will play a part in a scenario that includes walking, cycling and some form of public transit.

Minimobility and jitney-like buses or cars can also drive down the cost of total mobility. Based on our cost and network efficiency analysis, we find that platforms like Bzzt can achieve stable business operations and growth, with a user base that is consistent from month to month and dedicated to using this service. This further illustrates the trend of capturing latent demand for mobility that has played out over the ridesharing revolution. While this growth may have limits, we show in the case of Stockholm, ridership could actually increase. Geographically, for example, there could be significant benefit from targeted marketing campaigns to other districts within the municipality. At the same time core ridership in the central city can likely be maintained as growth occurs based on the trip types. 
What we find broadly is that minimobility can, in a functional way, extend lower priced rides to customers. It can fall into the universe of new mobility niches that offer sustainable alternatives to vehicular travel along with the more traditional ridesharing services that will continue to offer an emissions impact and lower fares to passengers. In the future, it may also be that even lower or free rides could be offered if the other revenue streams of minimobility can subsidize the price more than what is currently possible. In the case of Stockholm, vendors are continuing to experiment with this.

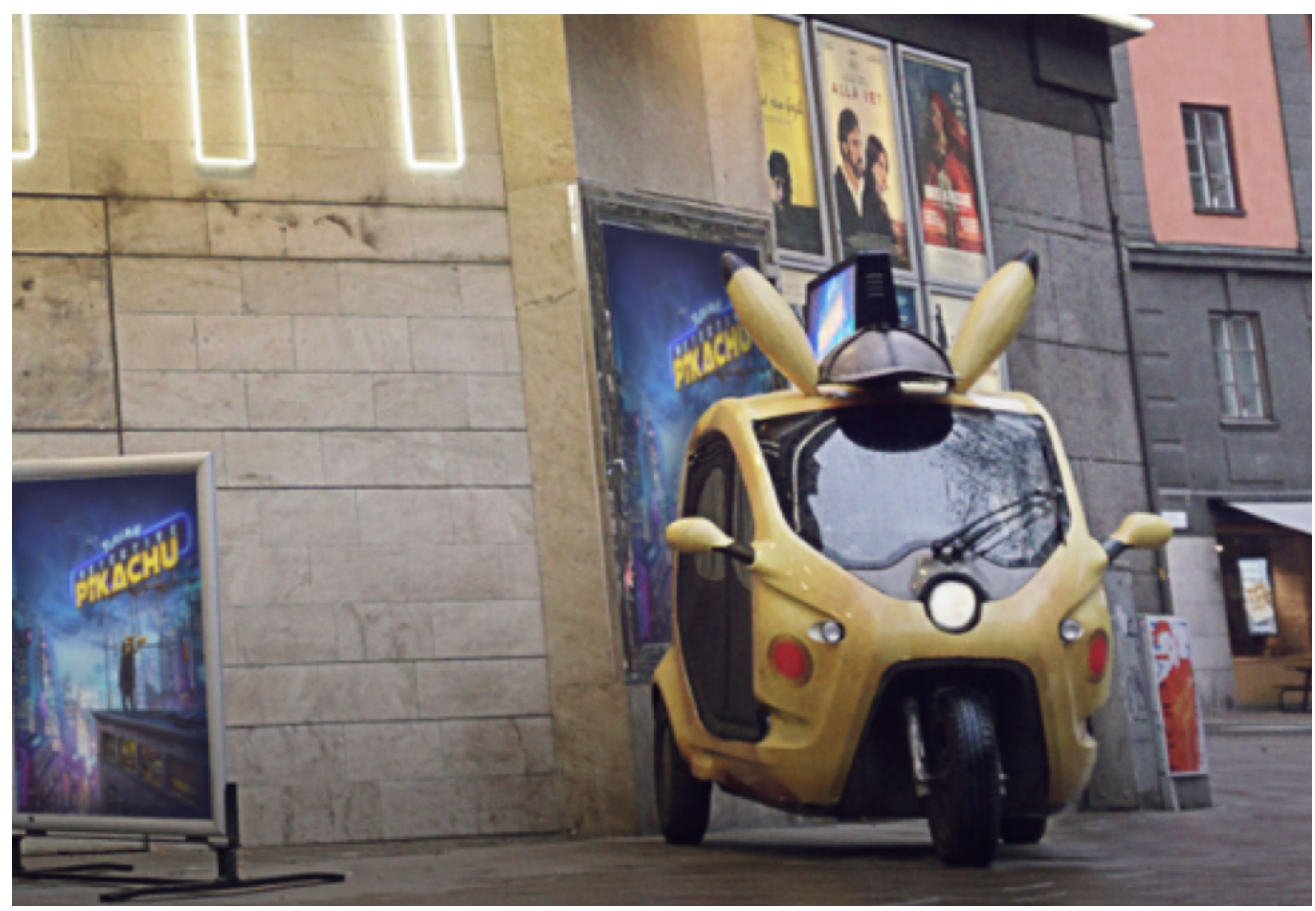

Figure 11: Pokemon Branded Vehicle

For example, including additional revenue sources such as corporate partnerships or advertising could improve the financial and affordability of these rides even more. Marketing campaigns could lower the price of minimobility. These include digital advertising with locally adapted content/campaigns (for example the Pokemon branded vehicle illustrated in Figure 11). Combining lastmile-logistics-related trips also holds promise; particularly in light of the surge in e-commerce and deliveries during the COVID-19 pandemic. Even with street data collection through various sensors attached or integrated into vehicles, perhaps scanning or mapping in real time, could make trips cheaper and more accessible.

Furthermore these platforms provide a convenient and comfortable form of travel that extends the suite of options to travelers. They provide a protected means of transport in inclement weather conditions that is faster than walking or cycling and cover more distance-and in the urban context, these results are very important. Classic research from Cervero and Duncan (2003) has solidified that even in the most walkable and bikeable cities, inclement weather poses some of the significant barriers to non-automotive travel and this trend is only compounded for women, children and those with reduced capacity (Cervero and Duncan 2003; Pucher and Buehler 2012; Riggs and Schwartz 2018). As cities across the globe struggle with traffic congestion-a trend only exasperated by the expansion of ridesharing-options are needed to reduce travel and improve roadway efficiency. The current minimobility vehicle takes up approximately one-third (1/3) of the space compared to a regular car and can still do almost the same transport job in the city (as the number of passengers most often are 1-2). Two-thirds of the space on streets and parking lots would be freed up if minimobility vehicles replaced regular cars. 
While this is a simplification since autos likely will be needed for transporting long in to the future-introducing new smaller platforms into cities is an important trend and the case of Bzzt in Stockholm shows that. If cities kept $20 \%$ of traffic volume as regular cars and introduced $40 \%$ minimobility platforms and $40 \%$ micromobility platforms, the spatial implications could be quite dramatic. Conceivable two-thirds $(2 / 3)$ of street space and two-thirds $(2 / 3)$ of parking space would be freed. Traffic flow might improve immensely and the time and price to travel decrease a lot which would help equality. The dollar cost time lost in traffic might decrease dramatically, alongside urban quality of life. More space could be given back to the city and citizens to use for improved aesthetics and accessibility, trees and ecosystem services that improve air quality, and we can imagine that cities would be increasingly great options for living for families with young children that previously would have moved out into the suburbs. Commerce in cities could increase with a healthier and more welcoming energy overall.

In this broader context it is important to emphasize that travel decisions and transportation networks do not happen in a vacuum but are influenced-by and can be conducive-to changes in the built environment. The locations where micro-taxi services can be successfully deployed generally have a mix land uses conducive to higher trip generation, even if they are not in the most dense locations in a city. Of equal import is street design and roadway capacity that allow for the safe and effective operation of on-demand vehicles. This safe, slow and sustainable built environment is not dissimilar to what many academics envisage in the future for the operation of autonomous vehicles (Riggs et al. 2019a, 2020, 2019b; Schlossberg et al. 2018). Sustainable mobility interventions from micro-taxis and autonomous shuttles to e-scooters and bicycles need clear signs, lines and multimodal built environment amenities that support safety for all roadway users.

\section{Conclusion}

Cities around the world are experimenting with new and disruptive forms of transportation and there has been ample discussion of the topic. This has included dialogue on emergent technology ranging from ridesharing services, to micro-mobility, to automated driving technology. This paper focuses on minimobility (or micro-electric-taxi-service), and specifically a case in Stockholm and the lessons that may hold for similar platform deployments-with the idea that the case offers a unique experiment worth thinking about in the transport future.

Using a comparative approach, we evaluate the potential that micro-mobility has to improve transit service efficiency while supporting efficiency and environmental goals. We show that platform provides a lower carbon footprint in urban conditions and reduces air pollution. The service provides a transport option between e-scooters and transportation network companies, what we frame as "mini transit service" or "minimobility." We show that these platforms can increase total access to travel in a low emission and cost-effective manner, and that ultimately they could be a part of a portfolio of zero-emission solutions for cities that includes walking, cycling and public transit.

Yet these results are not without policy questions. More work is needed to explore operational efficacy beyond Stockholm and particularly how these (as well as many other new platforms) platforms will be regulated. Furthermore questions remain on how companies in this space will: 1) address labor rules pertaining to minimum wages, treatment of drivers as employees, background checks and so on that are being debated for TNCs; 2) respond to fleet size caps designed to reduce VMT and deadheading / ghost miles driven without passengers; and 3) the built environment implication for this type of new on-demand mobility and how the platforms generate new travel behaviors that could change land use patterns over time. It is beyond the scope of this paper to model such changes in driver or passenger behavior, or to do scenario planning for how cities might grow and contract based on these disruptive innovations, however they do present opportunities for future work.

While these questions remain, it is clear that minimobility or pod-taxi platforms can provide the convenience of a ridesharing vehicle but at a price point closer to public transit. This can be achieved 
with zero emissions and fair working conditions for the drivers, with ridership catchment between 1-5 miles, and primary user volume from around 3 miles. This provides an opportunity to rethink urban transit platforms and access to mobility where cities have been able to provide transport beforemeeting a market where it is too far for users to walk, and too inefficient and costly for traditional transit, rideshare and taxis services to operate. 


\section{References}

Alemi, F., G. Circella, S. Handy, and P. Mokhtarian. 2018. What influences travelers to use Uber? Exploring the factors affecting the adoption of on-demand ride services in California. Travel Behaviour and Society, 13:88-104. ISSN 2214-367X. doi: 10.1016/j.tbs.2018.06.002. URL http://www.sciencedirect.com/science/article/pii/S2214367X17300947.

Anderson, D. N. 2014. "Not just a taxi"? For-profit ridesharing, driver strategies, and VMT. Transportation, 41(5):1099-1117.

Appleyard, B. and W. Riggs. 2018. "Doing the right things" before "Doing things right": A conceptual transportation/land use framework for livability, sustainability, and equity in the era of autonomous vehicles. In Transportation Research Board, 97th Annual Meeting.

Banister, D. 2008. The sustainable mobility paradigm. Transport Policy, 15(2):73-80.

Beutel, M. C., S. Gökay, W. Kluth, K.-H. Krempels, C. Samsel, and C. Terwelp. 2014. Product oriented integration of heterogeneous mobility services. In 17th International IEEE Conference on Intelligent Transportation Systems (ITSC), pp. 1529-1534. IEEE.

CB Insights. 2019. The micromobility revolution: How bikes and scooters are shaking up urban transport worldwide. Technical report, CB Insights.

Cervero, R. 2017. Mobility niches: Jitneys to robo-taxis. Journal of the American Planning Association, 83(4):404-412. Publisher: Taylor \& Francis.

Cervero, R. and M. Duncan. 2003. Walking, bicycling, and urban landscapes: Evidence from the San Francisco Bay Area. American Journal of Public Health, 93(9):1478.

Chan, N. D. and S. A. Shaheen. 2012. Ridesharing in North America: Past, present, and future. Transport Reviews, 32(1):93-112.

Circella, G. and F. Alemi. 2018. Chapter Five - Transport Policy in the Era of Ridehailing and Other Disruptive Transportation Technologies. In Y. Shiftan and M. Kamargianni, eds., Advances in Transport Policy and Planning, volume 1 of Preparing for the New Era of Transport Policies: Learning from Experience, pp. 119-144. Academic Press. doi: 10.1016/bs.atpp.2018.08.001. URL http://www.sciencedirect.com/science/article/pii/S2543000918300106.

Clewlow, R. R. and G. S. Mishra. 2017. Disruptive Transportation: The Adoption, Utilization, and Impacts of Ride-Hailing in the United States. Research Report UCD-ITS-RR-17-07, University of California, Davis, Institute of Transportation Studies, Davis, CA. URL https://itspubs.ucdavis. edu/wp-content/themes/ucdavis/pubs/download_pdf.php?id=2752.

Cohen, B. and J. Kietzmann. 2014. Ride on! Mobility business models for the sharing economy. Organization \& Environment, 27(3):279-296.

Cohen, B. and M. I. Winn. 2007. Market imperfections, opportunity and sustainable entrepreneurship. Journal of Business Venturing, 22(1):29-49.

Dijk, M., R. J. Orsato, and R. Kemp. 2013. The emergence of an electric mobility trajectory. Energy Policy, 52:135-145.

Gehrke, S. R., A. Felix, and T. G. Reardon. 2019. Substitution of ride-hailing services for more sustainable travel options in the Greater Boston region. Transportation Research Record, p. 0361198118821903. ISSN 0361-1981. doi: 10.1177/0361198118821903. URL https://doi. org/10.1177/0361198118821903.

Goldman, T. and R. Gorham. 2006. Sustainable urban transport: Four innovative directions. Technology in Society, 28(1-2):261-273.

Greenblatt, J. B. and S. Saxena. 2015. Autonomous taxis could greatly reduce greenhouse-gas emissions of US light-duty vehicles. Nature Climate Change, 5(9):860.

Greenblatt, J. B. and S. Shaheen. 2015. Automated vehicles, on-demand mobility, and environmental impacts. Current Sustainable/Renewable Energy Reports, 2(3):74-81.

Hall, J. D., C. Palsson, and J. Price. 2018. Is Uber a substitute or complement for public transit? Journal of Urban Economics, 108:36-50. ISSN 0094-1190. doi: 10.1016/j.jue.2018.09.003. URL 
http://www.sciencedirect.com/science/article/pii/S0094119018300731.

Hampshire, R., C. Simek, T. Fabusuyi, X. Di, and X. Chen. 2017. Measuring the Impact of an Unanticipated Disruption of Uber/Lyft in Austin, TX. SSRN Scholarly Paper ID 2977969, Social Science Research Network, Rochester, NY. URL https://papers.ssrn.com/abstract=2977969.

Hansen, E. G., F. Grosse-Dunker, and R. Reichwald. 2009. Sustainability innovation cube-a framework to evaluate sustainability-oriented innovations. International Journal of Innovation Management, 13(04):683-713.

Harb, M., Y. Xiao, G. Circella, P. Mokhtarian, and J. Walker. 2018. Projecting Travelers into a World of Self-Driving Cars: Naturalistic Experiment for Travel Behavior Implications. In Proceedings of the 97th Transportation Research Board. Washington D.C.

Hart, S. L. et al. 1997. Beyond greening: Strategies for a sustainable world. Harvard Business Review, 75(1):66-77.

Henao, A. and W. E. Marshall. 2018. The impact of ride-hailing on vehicle miles traveled. Transportation, pp. 1-22.

Hennessy, J. 2019. Avoided Emissions Framework innovation assessment of Bzzt. Technical report, Mission Innovation.

Kahle, D. and H. Wickham. 2013. ggmap: Spatial visualization with ggplot2. The R Journal, 5(1):144-161. URL https://journal.r-project.org/archive/2013-1/kahle-wickham.pdf.

Küster, F. and E. Lancaster. 2013. Bike carriage on long-distance trains: 7 basic services that give cyclist a smile. A collection of good practice examples from across Europe.

Lyons, G. and J. Urry. 2005. Travel time use in the information age. Transportation Research Part A: Policy and Practice, 39(2-3):257-276.

MacArthur, J., J. Dill, and M. Person. 2014. Electric bikes in North America: Results of an online survey. Transportation Research Record, 2468(1):123-130.

Nocerino, R., A. Colorni, F. Lia, and A. Luè. 2016. E-bikes and e-scooters for smart logistics: Environmental and economic sustainability in pro-E-bike Italian pilots. Transportation research procedia, 14:2362-2371.

Noland, R. B. and J. W. Polak. 2002. Travel time variability: A review of theoretical and empirical issues. Transport Reviews, 22(1):39-54.

Pucher, J. and R. Buehler. 2012. City Cycling. MIT Press. ISBN 978-0-262-30499-3.

Pucher, J. and L. Dijkstra. 2003. Promoting safe walking and cycling to improve public health: Lessons from the Netherlands and Germany. American Journal of Public Health, 93(9):1509-1516.

Riggs, W. 2018. Disruptive Transport: Driverless Cars, Transport Innovation and the Sustainable City of Tomorrow. Routledge.

Riggs, W. 2020. Telework and Sustainable Travel During the COVID-19 Era. SSRN Scholarly Paper ID 3638885, Social Science Research Network, Rochester, NY. URL https://papers.ssrn.com/ abstract $=3638885$.

Riggs, W., B. Appleyard, and M. Johnson. 2019a. A Design Framework for Livable Streets in the Era of Autonomous Vehicles. In Proceedings of the 98th Annual MeetingTransportation Research Board. Washington, D.C.

Riggs, W., B. Appleyard, and M. Johnson. 2020. A design framework for livable streets in the era of autonomous vehicles. Urban, Planning and Transport Research, 8(1):125137. ISSN null. doi: 10.1080/21650020.2020.1749123. Publisher: Routledge _eprint: https://doi.org/10.1080/21650020.2020.1749123, URL https://doi.org/10.1080/21650020. 2020.1749123.

Riggs, W. and S. A. Beiker. 2020. Business Models for Shared and Autonomous Mobility. In G. Meyer and S. Beiker, eds., Road Vehicle Automation 7, Lecture Notes in Mobility, pp. 33-48. Cham: Springer International Publishing. ISBN 978-3-030-52840-9. doi: 10.1007/978-3-030-528409 . 
Riggs, W., M. Ruhl, C. Rodier, and W. Baumgardner. 2019b. Designing Streets for Autonomous Vehicles. In G. Meyer and S. Beiker, eds., Road Vehicle Automation 6, Lecture Notes in Mobility, pp. 111-122. Springer International Publishing. ISBN 978-3-030-22933-7.

Riggs, W. and J. Schwartz. 2018. The impact of cargo bikes on the travel patterns of women. Urban, Planning and Transport Research, 6(1):95-110. ISSN null. doi: 10.1080/21650020.2018.1553628. URL https://doi.org/10.1080/21650020.2018.1553628.

Schaller, B. 2018. The New Automobility: Lyft, Uber and the Future of American Cities. Technical report, Schaller Consulting, New York, NY, USA. URL http://www.schallerconsult.com/ rideservices/automobility.pdf.

Schlossberg, M., W. W. Riggs, A. Millard-Ball, and E. Shay. 2018. Rethinking the street in an era of driverless cars. Technical report, University of Oregon Urbanism Next.

Shaheen, S. A., S. Guzman, and H. Zhang. 2010. Bikesharing in Europe, the Americas, and Asia: Past, present, and future. Transportation Research Record, 2143(1):159-167.

Sochor, J., H. Strömberg, and I. M. Karlsson. 2015. Implementing mobility as a service: Challenges in integrating user, commercial, and societal perspectives. Transportation Research Record, 2536(1):19.

Sperling, D. 2018. Three Revolutions: Steering Automated, Shared, and Electric Vehicles to a Better Future. Island Press. ISBN 978-1-61091-906-7. Google-Books-ID: 2URGDwAAQBAJ.

Vuchic, V. R. 2007. Urban transit systems and technology. John Wiley \& Sons. 